\title{
Produção de concreto autoadensável (CAA) com substituição parcial de cimento por metacaulim.
}

Self-compacting concrete (SCC) with partial replacement of cement by metakaolin

La producción de hormigón autocompactante (HAC) con sustitución parcial del

cemento por metacaolín

\author{
Alan Henrique Vicentini \\ Mestrando, UNESP, Brasil \\ vicentini.alanh@gmail.com \\ Marlon Boldrin Belluzi \\ Graduando, UNESP, Brasil \\ mbbelluzi@yahoo.com.br \\ Jorge Luís Akasaki \\ Professor Adjunto, UNESP, Brasil \\ akasaki@dec.feis.unesp.br
}




\section{RESUMO}

Novos tipos de concretos estão sendo desenvolvidos com o avanço da tecnologia e estudos, os quais são chamados de concreto de alto desempenho. Nossa pesquisa se baseia no concreto autoadensável com adição do fino metacaulim, possuindo como características: fluidez, resistência a segregação e capacidade passante, possibilitando o concreto a se adensar sem a presença de vibração, somente pelo seu próprio peso. Serão realizados os seguintes ensaios no estado fresco: abatimento de tronco de cone, abatimento de tronco de cone de Abrams, Funil V e Caixa L, com o objetivo de medir a coesão, segregação, fluidez e capacidade passante do mesmo. Já para o estado endurecido: resistência à compressão e à compressão diametral, absorção de água por imersão e por capilaridade e módulo de elasticidade.

PALAVRAS-CHAVE: Concreto autoadensável. Metacaulim. Adição mineral.

\section{ABSTRACT}

New types of concrete are being developed with the advancement of technology and studies, which are called high performance concrete. Our research is based on self-compacting concrete with the addition of fine metakaolin having the following characteristics: fluidity, segregation strength and passing ability, allowing the concrete to thicken without the presence of vibration, only by its own weight. The following tests will be performed on fresh: frustum abatement, trunk abatement Abrams cone, funnel $V$ and $L$ box, with the aim of measuring cohesion, segregation, flow and passing ability of it. As for the hardened state: compressive strength and diametral compression, water absorption by immersion and capillarity and modulus of elasticity.

KEYWORDS: Self Compacting Concrete. Metakaloin. Mineral admixture.

\section{ABSTRACTO}

Los nuevos tipos de hormigón están siendo desarrollados con el avance de la tecnología y los estudios, que se denomina hormigón de altas prestaciones. Nuestra investigación se basa en el hormigón autocompactante con la adición de metacaolín fino que tiene las siguientes características: fluidez, resistencia a la segregación y la capacidad de paso, permitiendo que el hormigón se espese sin la presencia de vibración, sólo por su propio peso. Las siguientes pruebas se realizarán en fresco: reducción de tronco de cono, el tronco de reducción de cono de Abrams, embudo $\mathrm{V}$ y $\mathrm{L}$ efectivo, con el objetivo de medir la cohesión, la segregación, el flujo y la capacidad de paso de la misma. En cuanto al estado endurecido: resistencia a la compresión y la compresión diametral, la absorción de agua por inmersión y capilaridad y módulo de elasticidad.

PALABRAS-CLABE: Hormigón Autocompactante. Metacaolín. Adición mineral. 


\section{INTRODUÇÃO}

A humanidade vem em crescente desenvolvimento e desde o surgimento do concreto, o mesmo vem sendo estudado e utilizado de forma esgotante, transformando-o em o material de construção mais utilizado no mundo, e consequentemente, é alavancado o uso de cimentos. O concreto convencional é composto, basicamente, por: cimento mais água, que é responsável pelo endurecimento da mistura e agregados, os quais fornecem resistência e tornam a mistura viável.

Em uma dessas variações do concreto, Okamura (1997) desenvolveu um concreto que possuía alta resistência à segregação e excelente deformabilidade no estado fresco. Este novo concreto possuía alta fluidez, resistência a segregação, e capacidade passante as quais possibilitaram o concreto a se adensar sem a presença de vibração, somente pelo seu próprio peso, sendo o único responsável, a ação da gravidade. A este concreto, se deu o nome de autoadensável.

Diferente do concreto convencional, o recém descoberto, possui dois novos materiais em sua composição, os quais são materiais finos e aditivos. Sendo ambos essenciais para sua formação, já que os finos dão a mistura, coesão e resistência a segregação, ocupando espaços que ficariam vagos, já os aditivos, modificam quimicamente, diminuindo a quantidade de água necessária a pasta e posteriormente, dando durabilidade e resistência ao concreto.

Segundo Bauer (2000), com a extração e produção de cimento, cerca de uma tonelada de gás carbônico é jogado na atmosfera para cada tonelada de cimento produzido. Isso, nos dias de hoje, equivale a $5 \%$ do total de $\mathrm{CO}_{2}$ que é jogado pra atmosfera, sendo então, a produção e extração de cimento, muito prejudicial ao meio ambiente, causando chuvas ácidas e poluição atmosférica. Alguns autores e pesquisadores acreditam que há possibilidade do efeito estufa ser causado pelo excesso de $\mathrm{CO}_{2}$ na atmosfera, e que este efeito, desestabilize o clima terrestre, porém, faltam evidências e conhecimento sobre o assunto.

Existem estudos que consistem em substituir o cimento parcialmente por adições mineiras, limitando a quantidade de gás carbônico liberado à atmosfera. Um desses minerais é o metacaulim, o qual será utilizado como substituinte mineral, no lugar do aglomerante, em porcentagens, no nosso estudo. Como material fino, o metacaulim vem ganhando mercado no Brasil e no mundo, e segundo a empresa METACAULIM DO BRASIL INDÚSTRIA E COMÉRCIO LTDA, (2011), metacaulim pode influenciar positivamente o concreto em vários aspectos, alguns itens serão citados: diminuição da porosidade e permeabilidade, reduzir a corrosão de armaduras, aumento da resistência à compressão.

\section{OBJETIVOS}

O objetivo primário desta pesquisa é estudar a viabilidade da produção de concreto autoadensável com utilização de metacaulim como material fino por meio do método de dosagem de Tutikian (2004). 


\section{MATERIAIS}

Para a produção de concreto autoadensável foram utilizados: cimento Portland CP II-Z-32 como aglomerante, areia média natural como agregado miúdo, brita basáltica como agregado graúdo, metacaulim como adição mineral, utilizado na substituição de parte de cimento Portland e aditivo superplastificante a base de policarboxilato. As características químicas do cimento Portland e do metacaulim estão na Tabela 1.

Tabela 1: Caracterização química do cimento e do metacaulim

\begin{tabular}{|c|c|c|c|c|}
\hline Cimento Portlan & II-Z-32 & $\begin{array}{c}\text { Especificações } \\
\text { NBR } \\
5736 / N B R \\
11578 \\
\text { máx. } \\
\end{array}$ & Metacaulim & Limites - NBR 15.894-1 \\
\hline $\mathrm{SiO}_{2}$ & 20,10 & - & 58,39 & $44,0 \%-65,0 \%$ \\
\hline $\mathrm{Fe}_{2} \mathrm{O}_{3}$ & 3,07 & - & 2,71 & - \\
\hline $\mathrm{Al}_{2} \mathrm{O}_{3}$ & 5,18 & - & 35,47 & $32,0 \%-46,0 \%$ \\
\hline $\mathrm{CaO}$ & 56,88 & - & 0,01 & \\
\hline MgO & 5,81 & 6,5 & 0,30 & $\mathrm{CaO}+\mathrm{MgO}<1,5 \%$ \\
\hline $\mathrm{SO}_{3}$ & 3,16 & 4,0 & - & $<1,5 \%$ \\
\hline $\mathrm{Na}_{2} \mathrm{O}$ & 0,13 & - & - & $<0,5 \%$ \\
\hline $\mathrm{K}_{2} \mathrm{O}$ & 0,76 & - & 1,44 & $<2,3 \%$ \\
\hline $\begin{array}{l}\text { Equivalente } \\
\text { Alcalino }\end{array}$ & 0,62 & - & - & - \\
\hline Cal livre em $\mathrm{CaO}$ & 2,31 & - & - & - \\
\hline
\end{tabular}

Fonte: COMPANHIA ENERGÉTICA DE SÃO PAULO - CESP

\section{DESCRIÇÃO DO MÉTODO DE DOSAGEM}

O método de dosagem escolhido foi o proposto por Tutikian (2004), no qual ele propõe a confecção de concreto autoadensável com materiais da região, sendo economicamente viável. O método de Tutikian é baseado no método IPT/EPUSP (Helene e Terzian, 1992) para concretos convencionais, com adaptações para transformá-lo em autoadensável com adição de finos e aditivos.

\section{ESCOLHA DOS MATERIAIS}

A escolha dos materiais foi feita conforme Tutikian (2004), sendo quaisquer materiais da região, desde que atendam condições básicas. Sendo assim, foram escolhidos os materiais da região de Ilha Solteira, sendo eles: agregado graúdo (brita basáltica) e miúdo (areia), cimento (Portland II-Z-32), Metacaulim (HP Ultra), aditivo (superplastificante à base de policarboxilato) e água, todos devidamente estudados e classificados segundo as normas regulamentadoras. 


\section{DETERMINAÇÃO DO TEOR DE ARGAMASSA}

Para determinação do teor de argamassa seca, partimos do método IPT/EPUSP, no qual nos deve-se partir de um teor de argamassa até que se encontre visualmente o melhor teor para o concreto. Nesta pesquisa, foi utilizado o traço 1:m, com $m$ igual a 5, iniciando com o teor de argamassa de $50 \%$ variando de $1 \mathrm{em} 1 \%$. Com isso, foi obtido o teor de argamassa seca ideal de $52 \%$, o qual permanecerá constante para todos os traços e famílias. A Tabela 2 contém os traços produzidos.

Tabela 2: Materiais utilizados para determinação do teor de argamassa.

\begin{tabular}{cccccccc}
\hline Teor $(\%)$ & C (kg) & A (kg) & B (kg) & Água $(\mathrm{kg})$ & \multicolumn{3}{c}{ Acréscimo } \\
\hline 50 & 6,67 & 13,33 & 20 & 3,8 & $\mathrm{C}(\mathrm{kg})$ & $\mathrm{A}(\mathrm{kg})$ & Água $(\mathrm{g})$ \\
51 & 6,8 & 14 & 20 & 3,8 & 0,13 & 0,67 & 1,24 \\
52 & 6,94 & 14,72 & 20 & 3,8 & 0,14 & 0,72 & 1,3 \\
53 & 7,25 & 16,23 & 20 & 3,8 & 0,31 & 1,51 & 1,32 \\
\hline
\end{tabular}

Fonte: ELABORAÇÃO DO PRÓPRIO AUTOR

\section{CÁLCULO DOS TRAÇOS}

Após obtido o teor de argamassa fixo, foram escolhidos os traços a serem confeccionados, sendo eles, um rico (1:3), dois intermediários (1:4,5 e 1:6) e um pobre (1:7,5). Estes traços foram confeccionados com duas substituições diferentes de finos e também, sem nenhuma adição. Os traços referência de cada família estão dispostos na Tabela 3.

Tabela3: Dosagem do concreto referência.

\begin{tabular}{cccccc}
\hline Teor (\%) & Traço & Cimento & Brita & Areia & Água \\
\hline 52 & $1: 7,5$ & 1 & 4,08 & 3,42 & 0,81 \\
52 & $1: 6$ & 1 & 3,36 & 2,64 & 0,65 \\
52 & $1: 4,5$ & 1 & 2,64 & 1,86 & 0,47 \\
52 & $1: 3$ & 1 & 1,92 & 1,08 & 0,37 \\
\hline
\end{tabular}

Fonte: ELABORAÇÃO DO PRÓPRIO AUTOR 


\section{ADIÇÃO DO ADITIVO}

Tutikian (2004) sugere que a adição de aditivo seja feita experimentalmente, sendo uma porcentagem da massa do aglomerante, e que não deve ser levada em conta a segregação nesta etapa, pois ela será corrigida com a adição do fino, neste estudo, o metacaulim. De acordo com a norma regulamentadora (NBR 11768), a qual fornece intervalo de substituição, chegamos a um valor experimental de $1 \%$ da massa de aglomerante como a massa de aditivo ideal para todos os traços, a qual permanecerá fixa.

\section{ADIÇÃO DO MATERIAL FINO}

Para corrigir a segregação, foi adicionado o metacaulim, o qual é um material fino, reativo e pozolânico. Com isto, o concreto precisará de uma maior quantidade de água, ou seja, deve-se aumentar a relação água/aglomerante. Contudo, é importante manter esta relação a menor possível, já que Tutikian (2004) afirma que com a menor relação a/ag, é possível se obter maior resistência e durabilidade.

Nosso estudo fixou uma quantidade de metacaulim e experimentalmente dosamos a quantidade necessária de água para cada traço. Contudo, o CAA deve passar pelos ensaios de trabalhabilidade dentro dos limites mínimo e máximos. A quantidade de metacaulim (MK) foi de 20 e $30 \%$ da massa do aglomerante.

Foram executados oito traços de concreto autoadensável, sendo 4 deles para uma substituição de $20 \%$ de metacaulim e 4 para $30 \%$ de metacaulim. As famílias foram: um rico (1:3), dois intermediários (1:4,5 e 1:6) e um pobre $(1: 7,5)$. Para a substituição de $20 \%$ da massa de aglomerante por metacaulim, foi realizada a dosagem da Tabela 4.

Tabela 4: Dosagem do CAA com $20 \%$ de MK

\begin{tabular}{ccccccc}
\hline Teor (\%) & Traço & Cimento & Metacaulim & Areia & Brita & Água \\
\hline 52 & $1: 7,5$ & 0.8 & 0.2 & 3,93 & 3,57 & 0,97 \\
52 & $1: 6$ & 0.8 & 0.2 & 3,06 & 2,94 & 0,74 \\
52 & $1: 4,5$ & 0.8 & 0.2 & 2,19 & 2,31 & 0,56 \\
52 & $1: 3$ & 0.8 & 0.2 & 1,32 & 1,68 & 0,41 \\
\hline
\end{tabular}

Fonte: ELABORAÇÃO DO PRÓPRIO AUTOR

Já para a substituição de $30 \%$ da massa de aglomerante por metacaulim, foi realizada a dosagem que é indicada na Tabela 5. 
Tabela 5: Dosagem do CAA com $30 \%$ de MK

\begin{tabular}{ccccccc}
\hline Teor (\%) & Traço & Cimento & Metacaulim & Areia & Brita & Água \\
\hline 52 & $1: 7,5$ & 0.7 & 0.3 & 3,93 & 3,57 & 1,05 \\
52 & $1: 6$ & 0.7 & 0.3 & 3,06 & 2,94 & 0,82 \\
52 & $1: 4,5$ & 0.7 & 0.3 & 2,19 & 2,31 & 0,66 \\
52 & $1: 3$ & 0.7 & 0.3 & 1,32 & 1,68 & 0,52 \\
\hline
\end{tabular}

Fonte: ELABORAÇÃO DO PRÓPRIO AUTOR

\section{ENSAIOS REALIZADOS}

Para analisar as características do concreto fresco, foram realizados ensaios normatizados. Para o concreto convencional (referência) foi realizado o abatimento de tronco de cone, para analisar a consistência do mesmo. Já para o CAA, os ensaios foram realizados para verificar a trabalhabilidade do mesmo, que consiste em: coesão, fluidez, segregação e capacidade passante. Os ensaios são descritos na Tabela 6. Todos foram feitos com equipamentos disponíveis no Laboratório de Engenharia Civil da UNESP de Ilha Solteira.

Tabela 6: Ensaios de caracterização reológica dos CAAs

\begin{tabular}{cccc}
\hline Ensaio & Norma vigente & Avalia & Valores aceitos \\
\hline Espalhamento de cone de Abrams & NBR 15823-2 & Fluidez e resistência à & Entre 600 e 750 mm \\
(Slump Flow Test) & NBR 15823-4 & Habilidade passante & Entre 0,8 e 0,9 \\
Ensaio da caixa-L (L-Box Test) & NBR 15823-5 & Viscosidade e fluidez & Entre 5 e 10 \\
Ensaio de funil V (V-Funnel Test) & & & segundos \\
\hline
\end{tabular}

Fonte: ELABORAÇÃO DO PRÓPRIO AUTOR

Os ensaios realizados no estado endurecido estão dispostos na Tabela 7.

Tabela 7: Ensaios realizados no estado endurecido

\begin{tabular}{ccc}
\hline Ensaio & Norma respectiva & Idades \\
\hline Resistência à compressão axial & NBR 5739 & 7,28 e 56 dias \\
Resistência à compressão diametral & NBR 7222 & 7,28 e 56 dias \\
Absorção de água por imersão & NBR 9778 & 7,28 e 56 dias \\
Absorção de água por capilaridade & NBR 9779 & 7,28 e 56 dias \\
Módulo de elasticidade & NBR 8522 & 7,28 e 56 dias \\
\hline
\end{tabular}

Fonte: ELABORAÇÃO DO PRÓPRIO AUTOR 


\section{RESULTADOS}

\section{ENSAIOS NO ESTADO FRESCO}

Após confecção dos concretos referências, ainda no estado fresco, foi realizado o ensaio do abatimento de tronco de cone, tendo todos os resultados dentro da faixa esperada, de 100 $\mathrm{mm} \pm 10 \mathrm{~mm}$, como indica a Tabela 8 .

Tabela 8: Ensaio do abatimento de tronco de cone para o concreto referência.

\begin{tabular}{cc}
\hline Traço & Ensaio de Slump (mm) \\
\hline $1: 7,5$ & 96,7 \\
$1: 6$ & 106,7 \\
$1: 4,5$ & 110 \\
$1: 3$ & 95 \\
\hline
\end{tabular}

Fonte: ELABORAÇÃO DO PRÓPRIO AUTOR

Após confecção dos CAAs, ensaios de trabalhabilidade foram realizados a fim de medir a fluidez, coesão, capacidade passante e a segregação do concreto. Os resultados estão nas Tabelas 9 e 10.

Tabela 9: Resultados dos ensaios realizados no CAA com substituição de $20 \%$ de MK por aglomerante

\begin{tabular}{cccc}
\hline Traço & Slump flow $(\mathrm{mm})$ & L-box $(\mathrm{h} 2 / \mathrm{h} 1)$ & V-Funnel \\
\hline $1: 3$ & 650 & 0,947 & 8 \\
$1: 4,5$ & 650 & 0,85 & 4 \\
$1: 6$ & 630 & 0,79 & 5 \\
$1: 7,5$ & 500 & 0,722 & 3 \\
\hline
\end{tabular}

Fonte: ELABORAÇÃO DO PRÓPRIO AUTOR

Tabela10: Resultados dos ensaios realizados no CAA com substituição de $30 \%$ de MK por aglomerante

\begin{tabular}{cccc}
\hline Traço & Slump flow $(\mathrm{mm})$ & L-box $(\mathrm{h} 2 / \mathrm{h} 1)$ & V-Funnel $(\mathrm{s})$ \\
\hline $1: 3$ & 650 & 0,875 & 3 \\
$1: 4,5$ & 680 & 0,989 & 2,4 \\
$1: 6$ & 635 & 0,84 & 3 \\
$1: 7,5$ & 610 & 0,94 & 3 \\
\hline
\end{tabular}

Fonte: ELABORAÇÃO DO PRÓPRIO AUTOR

Com estes resultados, verifica-se que o concreto referência possui uma aparência mais rígida, pois o mesmo, não é autoadensável e necessita de vibração para adensá-lo. O teste do 
abatimento de cone ficou dentro do esperado para todos os intervalos, cujo intervalo é de 90 a $110 \mathrm{~mm}$. Já o concreto autoadensável, em alguns ensaios, possuiu valores fora do intervalo convencional, o qual é de 600 a $800 \mathrm{~mm}$, como o slump flow do traço 1:7,5 com 20\% de MK. Todos os valores do V-Funnel ficaram fora do intervalo proposto, sendo de 5 segundos, exceto os traços 1:3 e 1:6 com 20\% de MK. Já no L-box, os valores ficaram no intervalo de 0,8 a 1 .

\section{ENSAIOS NO ESTADO ENDURECIDO}

Os resultados de resistência à compressão axial estão dispostos na Figura 1.

Figura 1: Gráfico correlacionando os traços pelas médias de resistência à compressão

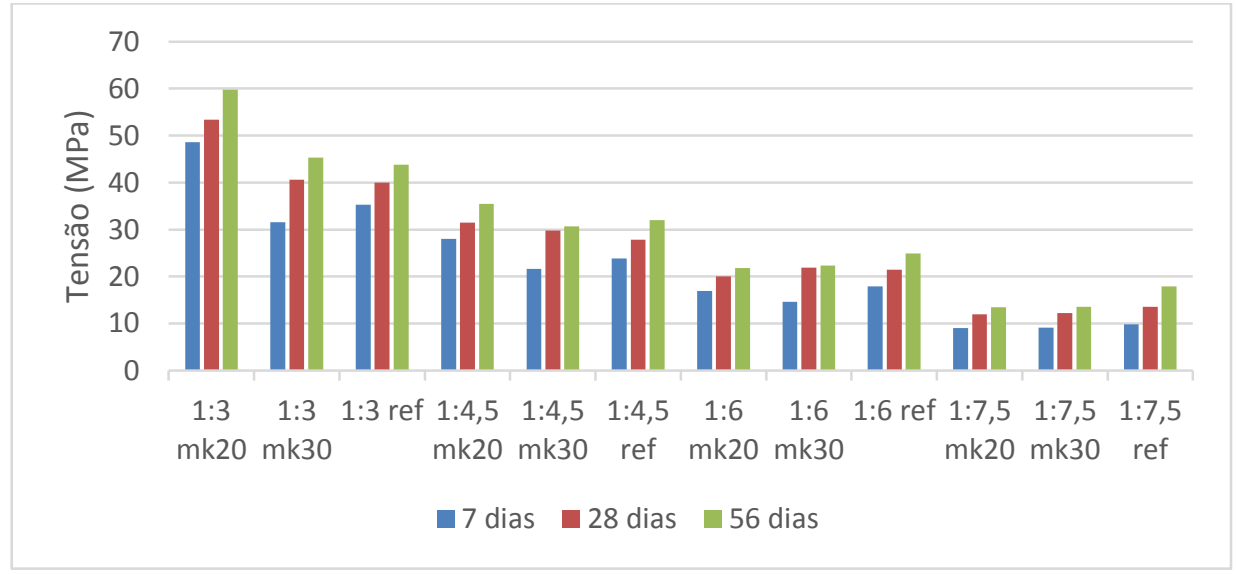

Fonte: ELABORAÇÃO DO PRÓPRIO AUTOR

Destacamos o alto valor de resistência à compressão obtida pelo traço $1: 3$ com $20 \%$ de substituição de metacaulim, tendo como resultado praticamente $60 \mathrm{MPa}$. Podemos atribuir este alto valor de resistência, ao preenchimento dos espaços vazios feito pelo material fino metacaulim. Também notamos, para todos os traços, um ganho da resistência ao passar da idade do traço. Por fim, podemos observar que os traços com 20 e $30 \%$ de substituição de metacaulim obtiveram resistências iguais ou maiores que a referência, mostrando que a substituição teve um efeito positivo na estrutura rígida.

Os resultados de resistência à compressão diametral estão dispostos na Figura 2. 
Figura 2: Gráfico correlacionando os traços pelas médias de resistência à compressão diametral

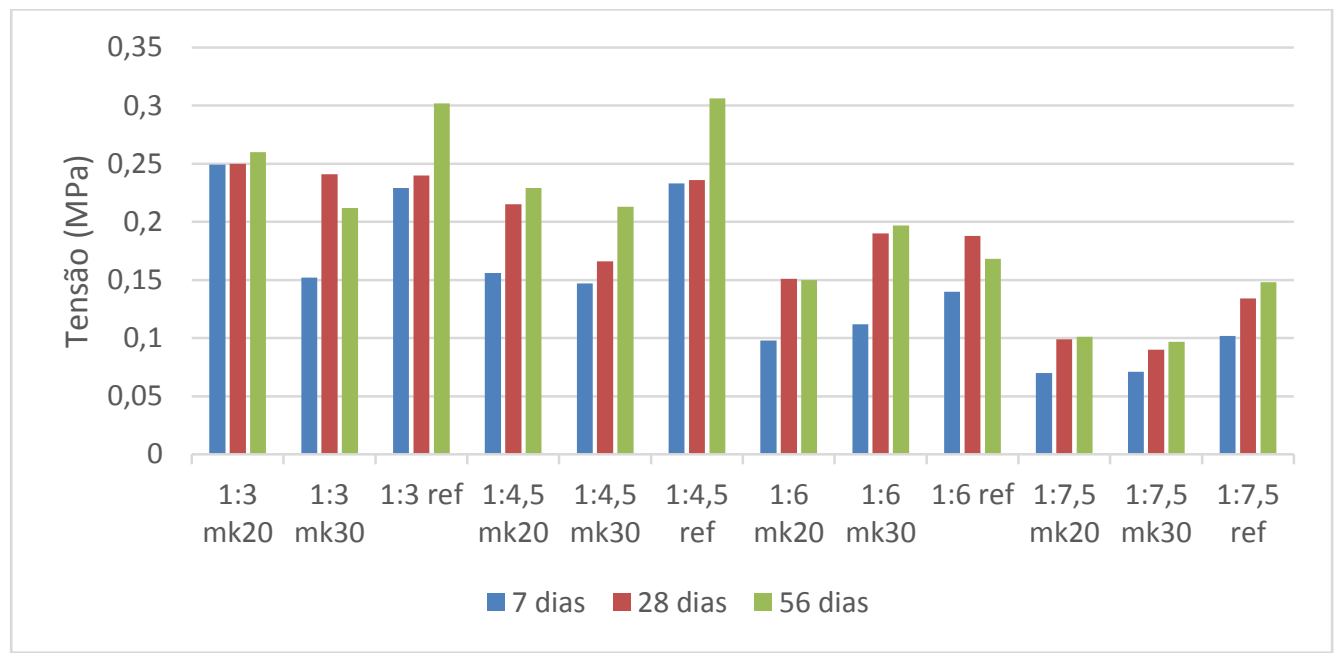

Fonte: ELABORAÇÃO DO PRÓPRIO AUTOR

Podemos notar na Figura 2 que a resistência à compressão diametral se elevou conforme a idade do concreto aumentava. Também, notamos que nos traços intermediários e no mais rico, os resultados foram próximos ao da referência. Já no traço pobre, o resultado ficou abaixo da referência, que podemos explicar pelo fato de possuir pouco material ligante, deixando-o menos rígido. Destacamos o traço 1:6 com mk 30, obtendo resultados maiores que o referência aos 28 e 56 dias, demonstrando um grande ganho de resistência.

Os resultados de módulos de elasticidade estão dispostos na Figura 3.

Figura 3: Gráfico correlacionando os traços pelas médias do módulo de elasticidade.

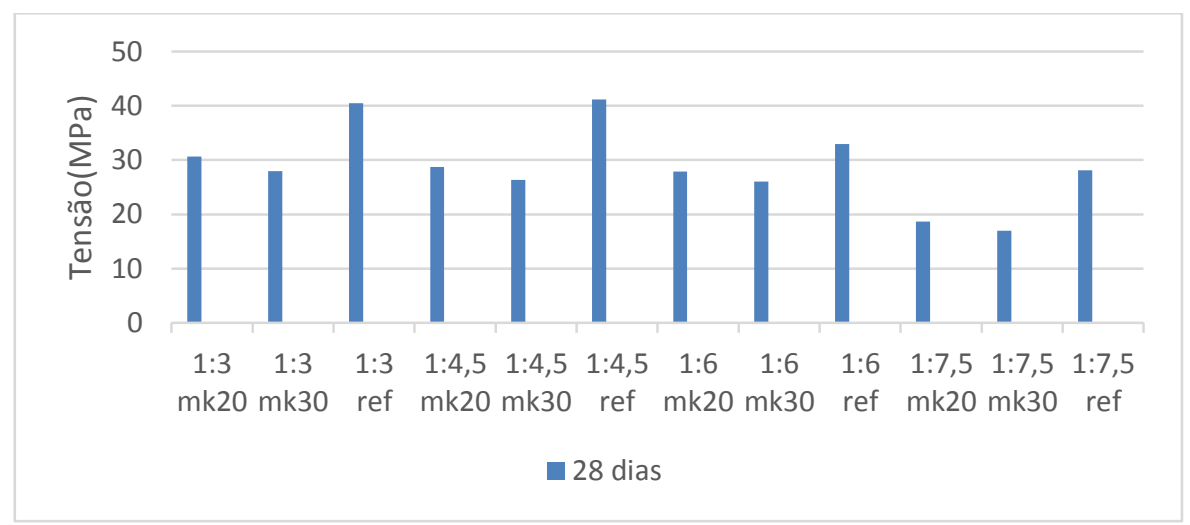

Fonte: ELABORAÇÃO DO PRÓPRIO AUTOR 
Pela pouca variação que ocorre no módulo de elasticidade em diferentes idades, o ensaio foi feito aos 28 dias. Notamos que os resultados foram padronizados, nos quais as maiores tensões suportadas foram pelas referências, seguido dos traços substituídos por $20 \%$ de metacaulim e por fim os de $30 \%$.

Os resultados de absorção de água por imersão estão dispostos na Figura 4.

Figura 4: Gráfico correlacionando os traços pelas médias da absorção de água por imersão.

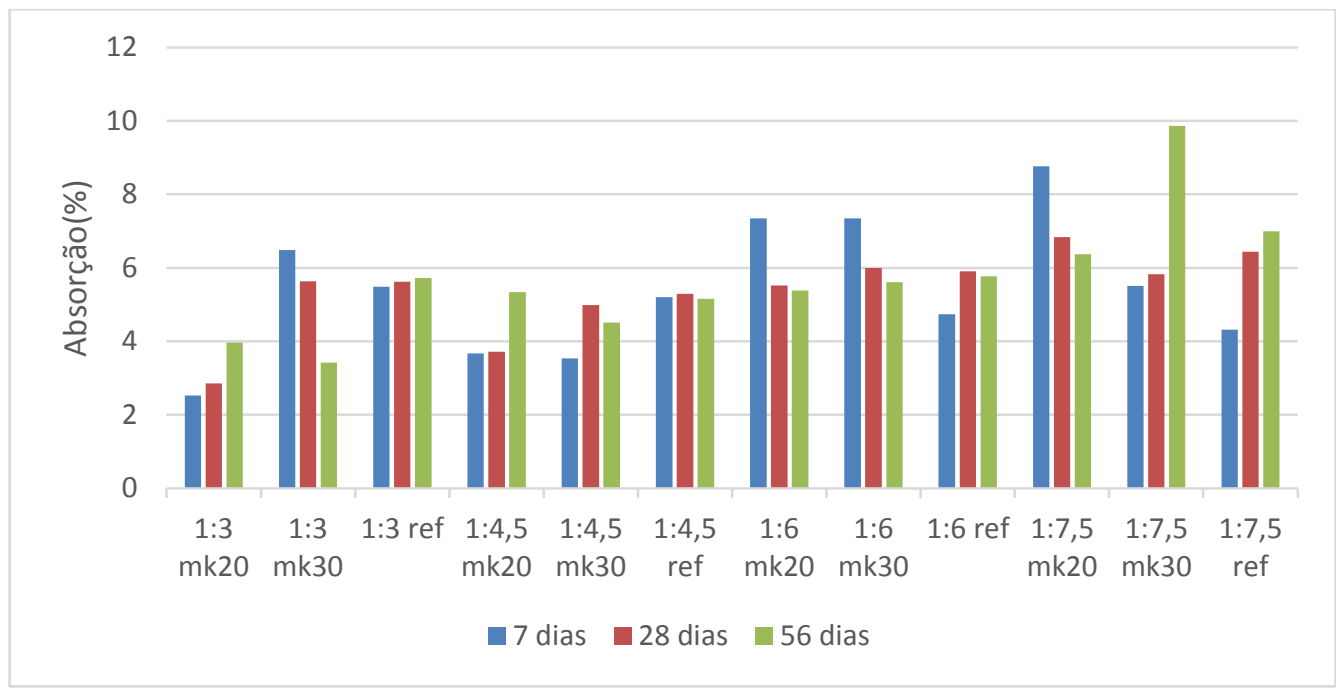

Fonte: ELABORAÇÃO DO PRÓPRIO AUTOR

Podemos observar que os traços intermediários e o rico atenderam a norma que limita a absorção em $6 \%$, exceto em alguns casos na idade de 7 dias, como no $1: 3$ com $30 \%$ de substituição de metacaulim por cimento, o 1:6 com 20 e 30\% de substituição, também aos 7 dias. Já o traço pobre obteve resultados acima deste valor. Podemos atribuir este alta absorção ao fato do traço possuir pouco aglomerante, ou seja, poucos finos para ocupar os vazios.

Os resultados de absorção de água por capilaridade estão dispostos na Figura 5. 
Figura 5: Gráfico correlacionando os traços pelas médias da absorção de água por capilaridade.

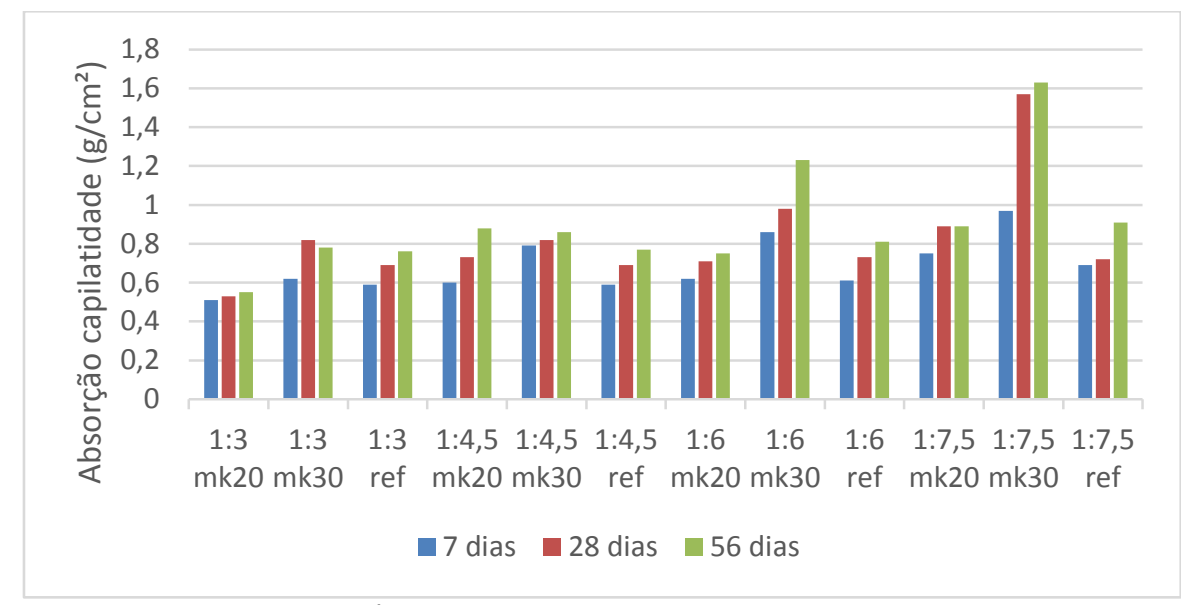

Fonte: ELABORAÇÃO DO PRÓPRIO AUTOR

Já na absorção por capilaridade, podemos observar uma tendência de aumento de absorção quanto maior a idade do traço. Porém, os resultados se aproximaram e em alguns casos até foram menores que o referência, mostrando-nos que o fino do metacaulim ajuda a ocupar vazios e diminuir a absorção por capilaridade. Os traços 1:6 e 1:7,5 com 30\% de substituição obtiveram resultados muito maiores que o da referência, podendo ser atrelado a erros de tendência, prática, teoria ou de experimento.

\section{CONCLUSÃO}

Este trabalho teve como objetivos produzir concreto autoadensável utilizando metacaulim e determinar o melhor teor de substituição de cimento pelo material, de forma a se produzir um concreto autoadensável com boas propriedades.

Através do método de Tutikian (2004), conseguimos determinar um teor de argamassa ideal para os concretos, o qual foi de 52\%. Também, experimentalmente, determinamos a porcentagem de aditivo comparada ao aglomerante em relação a massa, que foi de $1 \%$. As substituições de fino (metacaulim) por cimento, foram de 20 e 30\%, mantendo constante a massa de aglomerante. Com isso, tivemos condições de realizar as famílias de concreto e ensaia-los conforme sua consistência e trabalhabilidade, e também, nos CAAs, verificamos sua coesão, segregação, fluidez e capacidade passante.

Para o estado fresco, verificamos no CCV (referência) a consistência pelo ensaio de abatimento de tronco de cone. Todos os traços ficaram dentro do intervalo delimitado. Já no CAA, tivemos alguns problemas conforme os ensaios. Contudo, no geral, o ensaio de abatimento de tronco de cone de Abrams obteve valores dentro do esperado para a maioria dos traços, mostrando assim, que o concreto possuía pouca segregação e se mostrou bastante coeso.

Já para o estado endurecido, os ensaios mostraram que os finos do metacaulim ajudam a ocupar os vazios do concreto, pois houve uma tendência de a absorção tanto por imersão, quanto por capilaridade, diminuírem conforme adiciona-se o fino. Os resultados de absorção 
por imersão ficaram dentro da norma, exceto no traço pobre, o que já era esperado pela falta de aglomerante. Já na absorção por capilaridade, apenas dois traços apareceram com resultados fora do esperado, sendo muito maiores que o esperado pelo referência, sendo eles o 1:6 e 1:7,5 com $30 \%$ de substituição de metacaulim por cimento.

Por fim, concluímos que o metacaulim causou uma fluidez no concreto, que o auxiliou a se tornar CAA, também, diminuiu os espaços vazios com o preenchimento com material fino, diminuindo a absorção e podendo causar um aumento na durabilidade. Também, contribuiu para variação na resistência e no módulo de elasticidade do concreto, sendo que para a compressão simples (maior utilidade do concreto), houve um aumento significativo dos valores de tensões. Logo, foi viável a confecção de concreto autoadensável com metacaulim com os materiais disponíveis na região de Ilha Solteira - SP.

\section{AGRADECIMENTO}

Agradeço ao Conselho Nacional de Desenvolvimento Científico e Tecnológico, pela bolsa estudantil concedida ao discente para o desenvolvimento do estudo.

\section{REFERÊNCIAS BIBLIOGRÁFICAS}

ASSOCIAÇÃO BRASILEIRA DE NORMAS TÉCNICAS. 15823: Concreto autoadensável. Rio de Janeiro, 2010.

ASSOCIAÇÃO BRASILEIRA DE NORMAS TÉCNICAS. NBR 5739: Concreto - Ensaio de compressão de corpos de prova cilíndricos. Rio de Janeiro, 2007.

ASSOCIAÇÃO BRASILEIRA DE NORMAS TÉCNICAS. NBR 8522 - Concreto - Determinação do módulo estático de elasticidade à compressão. Rio de Janeiro, 2008.

ASSOCIAÇÃO BRASILEIRA DE NORMAS TÉCNICAS. NBR 9778: Argamassa e concreto endurecidos Determinação da absorção de água, índice de vazios e massa específica. Rio de Janeiro, 2005.

ASSOCIAÇÃO BRASILEIRA DE NORMAS TÉCNICAS. NBR 7222 - Argamassa e Concreto - Determinação da Resistência a tração por compressão diametral de corpos-de-prova cilíndricos. Rio de Janeiro, 1994.

ASSOCIAÇÃO BRASILEIRA DE NORMAS TÉCNICAS. NBR 9778 - Argamassa e concreto endurecido Determinação da absorção de água por imersão - Índices de vazios e massa específica. Rio de Janeiro, 1987.

ASSOCIAÇÃO BRASILEIRA DE NORMAS TÉCNICAS. NBR 9779 - Argamassa e concreto endurecido Determinação da absorção de água por capilaridade. Rio de Janeiro, 1995.

BAUER, L. A. F. MATERIAIS DE CONSTRUÇÃO. 5. ed. Uberlândia: Ltc, 2000. p.447

HELENE, P. Dosagem dos concretos de cimento Portland. In: Concreto: ensino, pesquisa e realizações. Ed: G.C. ISAIA. São Paulo, volume, capítulo 15, pg.440-470, 2005. 
METACAULIM DO BRASIL (São Paulo). FICHA DE INFORMAÇÃO DE SEGURANÇA DE PRODUTOS QUÍMICOS - FISPQ (NBR 14725/2002). Jundiaí, 2011.

OKAMURA, H. Self-compacting High-performance concrete. In: Concrete International, v. 19, n.7 p. $50-$ 52, Julho 1997.

PETERSSEN, B.G; REKNES, K. Advances in self-compacting concrete with lignosulphonate superplasticizer. In: fourth International RILEM Symposium on Self-compacting Concrete. Chicago, EUA, 2005.

TUTIKIAN, B. F. Método para dosagem de concretos auto-adensáveis. 2004.149 f. Dissertação (Mestrado) - Curso de Engenharia Civil, Universidade Federal do Rio Grande do Sul, Porto Alegre, 2004.

TUTIKIAN, B. F. Proposição de um método de dosagem experimental para concretos auto-adensáveis. 2007. 163 f. Tese (Doutorado) - Curso de Engenharia Civil, Universidade Federal do Rio Grande do Sul, Porto Alegre, 2007.

TUTIKIAN, B. F.; DAL MOLIN, D. C. Concreto auto-adensável. Porto Alegre: Pini, 2008. 144 p.

VON PAUMGARTTEN, M. D. Concreto auto-adensável com materiais encontrados na região de Belém. 2010. 69 f. TCC (Graduação) - Curso de Engenharia Civil, Universidade da Amazônia, Belém, 2010. 